\title{
Health education compliance among pregnant women
}

\author{
Azza Fathi Ibrahim Mohammed*1, Hanan Abdelrahman Mostafa Kandeel ${ }^{2}$ \\ ${ }^{1}$ Nursing Education Department, Faculty of Nursing, Alexandria, Egypt \\ ${ }^{2}$ Gynecology and Obstetrics Nursing Department, Faculty of Nursing, Alexandria, Egypt
}

Received: April 19, 2017

DOI: $10.5430 /$ cns.v5n3p46
Accepted: June 14, 2017

Online Published: July 10, 2017

\begin{abstract}
It has been publicized that pregnant women exhibit an increase in clinical signs and symptoms during the pregnancy period. Nurses have an essential role to help pregnant women in handling their self-care as independently as possible. Health education is a foundation of nursing interventions in prenatal care. The compliance of pregnant women to health instructions will facilitate the nursing management in being systemic, holistic and creative for experiencing a positive pregnancy outcome. But, despite all the best intentions and efforts on the part of the healthcare professionals, these products might not be achievable if the women are non-compliant. Therefore, the aim of this study is to determine the factors that affect health education compliance among pregnant women. A descriptive research design was undertaken. By convenient sampling, 238 pregnant women were selected at out-patients units in El Shatiby University Hospital, Alexandria, Egypt. A Health Education Compliance Questionnaire (HECQ) was developed and used to collect the necessary data of the study. Based on the analysis of the subjects' responses, the results revealed that there were promoting and inhibiting factors regarding health education compliance as perceived by pregnant women. First, in relation to themselves, the enhancing factors were physical and psychological conditions, self-cooperation, and relationship with the health staff, whereas, the inhibiting factors were concentration and understanding, acceptance, and trust. Second, as regards social and economic factors, the promoting factors were friends and relatives, family relationships, and marital age, while the hindering factors were monthly income, family size and transportation. Moreover, study subjects ranked the satisfactory topics that they received and adhered pregnancy follow up took the first position and dangerous signs were the next. In conclusion, compliance to health education among pregnant women is a major health concern affecting almost all women in El Shatiby University Hospital. There are a lot of factors that may promote or inhibit health education compliance among these women. The major recommendation is that nurses as health educators must facilitate the educational process for pregnant women, family and society. Efforts and collaboration between all nursing disciplines in the field of health education should be established. As this may be crucial to improve health education compliance within pregnancy or other maternal condition. Future studies need to investigate on how to minimize the inhibiting factors and support the promoting ones.
\end{abstract}

Key Words: Health education, Pregnant women compliance, Factors

\section{INTRODUCTION}

Despite the fact that the greatest number of labor and pregnancies occur in a healthy manner, many pregnancies are at risk. About $15 \%$ of all pregnant women have possibly dangerous complications. Some need antenatal interference and others require complicated obstetrical intervention to survive. Nurses, midwives and doctors are the professionals who are responsible for the care of women during pregnancy, childbirth and in the postnatal period. To attain optimal support for safe maternal health, all health sectors in maternity and women healthcare facilities, should focus on promoting health education and instructional activities that expands

\footnotetext{
*Correspondence: Azza Fathi Ibrahim Mohammed; Email: azza_fathy2008@yahoo.com; Address: Faculty of Nursing, Alexandria, Egypt.
} 
knowledge, attitudes and practices of mothers, their families and the community in relation to healthy pregnancies and childbirth. ${ }^{[1,2]}$

The ultimate goal of any nursing educational intervention is to help pregnant women to be as self-dependent as possible and to assess or manage the danger signs in the antenatal stage. Health education is one of the most important approaches used in improving pregnancy literacy. It encourages modifying behaviors voluntarily to promote healthy ones and helps in dealing with a variety of situations in the pregnancy trimesters. In Egypt, there is great effort from the Ministry of Health and the World Health Organization in supporting and promoting health education for women, particularly in the prenatal period. However, many pregnant women are noncompliant to this health education assistance. Health education considers all care activities needed for pregnancy management. ${ }^{[3-5]}$

Compliance means the actions of obeying and following rules, instructions or requests. Moreover, in health fields, it can be defined as the capability and readiness or willingness to accept and follow a prescribed healthcare management. Adherence is frequently used interchangeably with compliance. Health compliance in clinical healthcare is determined by the nature of teaching content in the related health education. Compliance can be belonging to medications (dose, name, and time), nutritional follow (composition and number of meals) self-care dependency, nutritional follow-up, seeking healthcare, implementing an exercise regimen, and so on. The satisfactory levels of compliance were different in several trials. Thus, there was no specific standardized or approved measurement to determine acceptable compliance. Many references pointed to $80 \%$ of performance of the desired task to be considered as accepted compliance. ${ }^{[2,4,6]}$

There are several studies on pregnant women and noncompliance to health instruction, but the investigations on the factors affecting pregnancy compliance to health education are minimal. These factors can be positively or negatively classified. There are a few reviews focused on the determination and description of these different factors. ${ }^{[4,7]}$ Therefore, the aim of the current study is to determine the views of pregnant women in relation to the factors that affect health education compliance. Investigating their awareness and opinions concerning this issue will be an important step for improving and promoting positive factors and overcoming negative ones. Compliance to health education can be the only care management for pregnancy and can enhance the overall pregnancy outcomes. This paper is considered an important study regarding compliance in health education and will be a great guide for nurses as health educators.

Published by Sciedu Press

\section{Research Question:}

What are the factors affecting health education compliance as perceived by pregnant women?

\section{MATERIAL AND METHOD}

A descriptive research design was employed in the present study. A convenient sample was comprised of 238 pregnant women who accepted to participate. They were in various pregnancy trimesters, could read and write, and were free from any associated illnesses. They met the researcher mostly in the morning during their pregnancy follow-up visits. The sample size was determined based on the Epidemiological Information Statistical Program, which estimated that a minimal number should be 220. The Health Education Compliance Questionnaire (HECQ) was developed and applied by the researcher based on a thorough review of related literature ${ }^{[1,3,4,8]}$ to assess the factors that affected women's compliance to health education during the pregnancy period. This tool involved multiple choice questions, with two to seven alternatives. The correct answer took the highest score. The questions were concerned with factors regarding the pregnant women themselves, social and economic factors, and staff and health setting factors.

This instrument approved the accepted reliability by Cronbach Alpha Coefficient test (0.71 to 0.75$)$ and was revised for validity by five experts in nursing education, obstetric nursing and obstetric medicine fields.

Official permission and approvals were obtained from the study setting and the Ethical Committee of the Faculty of Nursing, University of Alexandria, Egypt. Written consents were obtained from the study subjects. A pilot study was done on 23 pregnancies that were separate from the study sample. The study instrument was distributed to study participants in the attendance of the researcher for any clarifications. Anonymity and complete confidentiality were ascertained.

\section{Statistical analysis}

Data was fed, coded, revised and analyzed using a PC with Statistical Packages for Social Science (SPSS 20), Version 10.0, for Windows. The results were estimated using numbers and percentage.

\section{Results}

Table 1 showed that nearly half $(44.5 \%)$ of the subjects were in their thirties and slightly less than this percent in their teens (42.9\%). Approximately half of the women (49.6\%) came from urban residences. More than one half of them (52.1\%) were with moderate education. Only less than one third $(30.2 \%)$ of the pregnant women were housewives. Moreover, 
more than one half of them $(29.4 \% \& 28.6 \%$ combined) had follow-up visits 2 to 3 times/month during their pregnancies. The majority $(80.7 \%)$ of the participants were not smokers and about half (45\%) of them complained from gastric upset. All of the subjects $(100 \%)$ had attended previous antenatal care health education.

Table 1. Distribution of the pregnant women according to their personal characteristics

\begin{tabular}{|c|c|c|}
\hline \multirow{2}{*}{ Personal characteristics } & \multicolumn{2}{|c|}{ Total $(n=238)$} \\
\hline & No & $\%$ \\
\hline \multicolumn{3}{|l|}{$\underline{\text { Age }}$} \\
\hline - $15 \leq 20$ & 102 & 42.9 \\
\hline - $20 \leq 30$ & 30 & 12.6 \\
\hline - $30 \leq 40$ & 106 & 44.5 \\
\hline \multicolumn{3}{|l|}{ Residence } \\
\hline - Upper Egypt & 49 & 20.6 \\
\hline - Urban & 118 & 49.6 \\
\hline • Rural & 71 & 29.8 \\
\hline \multicolumn{3}{|l|}{ Education level } \\
\hline - Read \& write & 112 & 47.1 \\
\hline - Moderate & 124 & 52.1 \\
\hline - High education & 2 & 0.8 \\
\hline \multicolumn{3}{|l|}{ Occupation } \\
\hline - Worker & 88 & 37.0 \\
\hline - Employee & 25 & 10.5 \\
\hline - Farmer & 53 & 22.3 \\
\hline - Housewife & 72 & 30.2 \\
\hline \multicolumn{3}{|c|}{ Number of follow up visits/month } \\
\hline - 1 & 54 & 22.7 \\
\hline - 2 & 70 & 29.4 \\
\hline - 3 & 68 & 28.6 \\
\hline - 4 & 22 & 9.2 \\
\hline$\bullet 5$ & 24 & 10.1 \\
\hline \multicolumn{3}{|l|}{$\underline{\text { Smoking }}$} \\
\hline - Yes & 46 & 19.3 \\
\hline - No & 192 & 80.7 \\
\hline \multicolumn{3}{|c|}{ Associated pregnancy dangerous signs } \\
\hline - Headache & 42 & 17.6 \\
\hline - Gastric upset & 107 & 45.0 \\
\hline - Respiratory complain & 32 & 13.4 \\
\hline • None & 57 & 23.9 \\
\hline \multicolumn{3}{|c|}{ Received previous health education about antenatal care } \\
\hline - Yes & 238 & 100 \\
\hline - No & 0.00 & 0.00 \\
\hline
\end{tabular}

Table 2 clarified the factors that were perceived by pregnant women related to themselves. The majority $(88.2 \%$, $93.3 \%, 88.6 \% \& 94.5 \%$ ) of the study subjects perceived that physical and psychological conditions, self-cooperation, and relationship with health staff, were the apparent promoting factors for health education compliance. On the other hand, great proportions $(82.7 \%, 73.9 \%, 94.5 \% \& 83.2 \%)$ of them, viewed that concentration and understanding, acceptance, trust, and health beliefs were the factors that most hindered health education compliance.

Table 3 revealed the factors that were perceived by the study participants related to social and economic aspects. High proportions of them $(79.4 \%, 87.8 \%$ and $70.6 \%)$ recognized that friends and relatives, family relationship, and marital age, were the obvious promoting factors for health education compliance. However, the majority $(94.9 \%, 90.7 \%$ \& $70.6 \%)$ of the pregnant women found that monthly income, family size, and transportation were the most noticeable factors that inhibit health education compliance.

The data in Table 4 represented the factors that were perceived by study participants related to health staff and setting. There was a high percent of study subjects $(84.03 \%$ $\& 88.6 \%$ ) that chose staff cooperation and teaching materials and content as the factors having the most positive effect on health education compliance. While for inhibiting factors, the majority of pregnant women $(83.2 \%, 85.7 \%, 79.4 \%$, $\& 78.15 \%$ ) viewed that staff knowledge and training, health communication skills, and health education time were the obvious ones.

Figure 1 illustrated the ranking of the study subjects to the health education topics according to their compliance. They ranked the follow-up visits as the first educational content that gained their compliance $(42.4 \%)$. Their second rank was the dangerous signs content $(23.8 \%)$. The remaining teaching contents ranked with minimal proportions.

\section{Discussion}

Health education in pregnancy is one of the most important concerns in the health care system. The majority of ante-natal problems can be solved through health education. Pregnancy can have risky physical, psychological or social consequences. The risk can affect not only the mother, but also the fetus. Maternal health education is a significant issue of the nursing plan of interventions in the ante-natal phase. Proper health teaching has a proven positive outcome for the woman and her baby. ${ }^{[4,9,10]}$ Health education in pregnancy is important, but it is useless without compliance.

In relation to a subject's personal data, the current study illustrated that nearly half $(44.5 \%)$ of the subjects were in their thirties with slightly less than this in their teens (42.9\%). Early marriage was common in the Egyptian culture. This was supported by Mersal et al., in 2013, who conducted a study in Egypt which discussed that while the permitted age for marriage in Egypt was 16 years for females, the actual observed mean age was 15.33 years. This proved that 
the Egyptian society still preferred early marriage for girls. gious with high benefits in marriage, children must be gotten Furthermore, in the same line, in India, mothers indicated early. This was a significant reason for early marriage among parallel results as highlighted by Mukhopadhyay et al., in Egyptian girls. $2010 .{ }^{[4,11]}$ Egyptian women think that in order to be presti-

Table 2. Distribution of the study subjects according to perceiving factors that promote or inhibit their compliance to health education (in themselves)

\begin{tabular}{|c|c|c|c|c|}
\hline \multirow{3}{*}{ *Factors that promote or inhibit compliance in clients } & \multicolumn{4}{|c|}{ Total number $n=238$} \\
\hline & \multicolumn{2}{|c|}{ Promoting factors } & \multicolumn{2}{|c|}{ Inhibiting factors } \\
\hline & No. & $\%$ & No. & $\%$ \\
\hline Concentration and understanding & 36 & 15.1 & 197 & 82.7 \\
\hline Acceptance & 69 & 28.9 & 176 & 73.9 \\
\hline Trust in knowledge given & 47 & 19.7 & 222 & 94.5 \\
\hline Psychological condition & 210 & 88.2 & 57 & 23.9 \\
\hline Physical condition & 222 & 93.3 & 68 & 28.6 \\
\hline Learning readiness \& motivation & 98 & 41.18 & 188 & 78.9 \\
\hline Cooperation & 211 & 88.6 & 45 & 18.9 \\
\hline Health beliefs & 45 & 18.9 & 198 & 83.2 \\
\hline Relationship with health staff & 225 & 94.5 & 54 & 22.7 \\
\hline
\end{tabular}

Note. ${ }^{*}$ Subjects allowed to choose more than one answer

Table 3. Distribution of the study subjects according to perceiving factors that promote or inhibit their compliance to health education in social \& economic aspects

\begin{tabular}{|c|c|c|c|c|}
\hline \multirow{3}{*}{$\begin{array}{l}{ }^{*} \text { Factors that promote or inhibit compliance in social \& } \\
\text { economic aspect }\end{array}$} & \multicolumn{4}{|c|}{ Total number $n=238$} \\
\hline & \multicolumn{2}{|c|}{ Promoting factors } & \multicolumn{2}{|c|}{ Inhibiting factors } \\
\hline & No. & $\%$ & No. & $\%$ \\
\hline Monthly income & 16 & 6.7 & 226 & 94.95 \\
\hline Friends and relatives & 189 & 79.4 & 55 & 23.1 \\
\hline Family size & 67 & 28.15 & 216 & 90.75 \\
\hline Family relationship & 209 & 87.8 & 57 & 23.9 \\
\hline Transportation & 24 & 10.08 & 168 & 70.6 \\
\hline Family leader decision & 55 & 23.1 & 33 & 13.9 \\
\hline Work nature & 21 & 8.8 & 107 & 44.95 \\
\hline Marital age & 168 & 70.6 & 56 & 23.5 \\
\hline
\end{tabular}

Note. ${ }^{*}$ Subjects allowed to choose more than one answer

Table 4. Distribution of the study subjects according to perceiving factors that promote or inhibit their compliance to health education in health staff \& setting

\begin{tabular}{|c|c|c|c|c|}
\hline \multirow{3}{*}{$\begin{array}{l}{ }^{*} \text { Factors that promote or inhibit compliance in health } \\
\text { staff and setting }\end{array}$} & \multicolumn{4}{|c|}{ Total number $n=238$} \\
\hline & \multicolumn{2}{|c|}{ Promoting factors } & \multicolumn{2}{|c|}{ Inhibiting factors } \\
\hline & No. & $\%$ & No. & $\%$ \\
\hline Staff knowledge and training & 45 & 18.91 & 198 & 83.2 \\
\hline Health communication skills & 33 & 13.8 & 204 & 85.7 \\
\hline Staff cooperation & 200 & 84.03 & 67 & 28.15 \\
\hline Health education time & 56 & 23.5 & 189 & 79.4 \\
\hline Teaching materials and content & 211 & 88.6 & 47 & 19.7 \\
\hline Health education venue & 37 & 15.5 & 186 & 78.15 \\
\hline
\end{tabular}

Note. ${ }^{*}$ Subjects allowed to choose more than one answer 


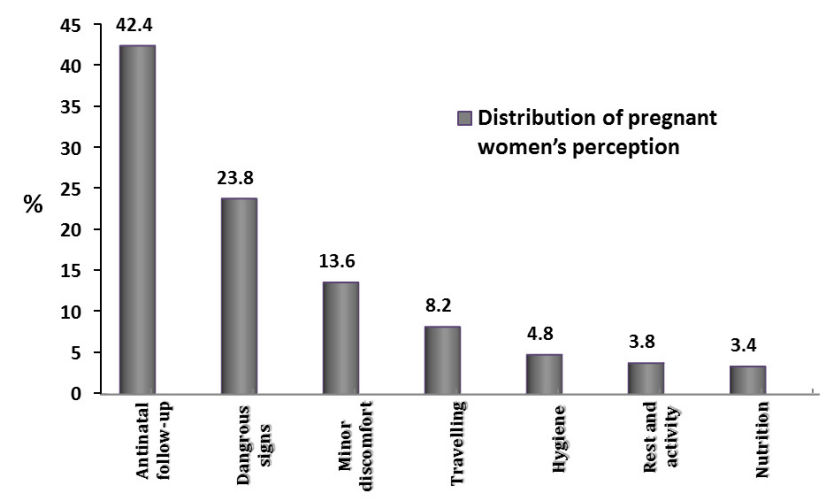

Figure 1. Distribution of pregnant women's perception to the rank of health education topics according to their compliance, as presented by percentages

Moreover, a high percent of the subjects were from urban areas, which particularly tended to seek health care more than any other areas in Egypt. This was similar to Fathi et al., in 2016, who reported that the nature of life in urban areas of Egypt encourages people to be more responsible, independent and more likely to attain health advice. Dissimilar to this point, Gaber and Mostafa in 2013, stated that urban life in Egypt was very busy which hindered people to keep health follow-up visits. ${ }^{[12,13]}$ The majority of current participants came from urban areas and all of them attended previous ante-natal care health education. This proved their initiation to seek health information and health care services.

A significant percent of the women had moderate education, which proved their abilities in providing clear views about their compliance in health education. Harmonious to this idea, Ibrahim \& Ibrahim in 1998 mentioned that educated women could manage their reproductive health appropriately and seek right health advice. Likewise, Gharaibeh et al., in 2005 recommended that education has a greater effect on women's choices and adherence. ${ }^{[14,15]}$ Fortunately, educated pregnancies had better health and childbirth outcomes.

More than half of the subjects received maternal follow up two to three times a month, which reflected their commitment to obtain guidance and health support. Inconsistent to this aspect, the demographic data about females in Indonesia highlighted that there were still misconceptions regarding the value of healthcare visits. ${ }^{[16]}$ Furthermore, the majority of pregnant women, in the current study, were experiencing gastric upset as a pregnancy minor discomfort, which was common among pregnancies in Arabian countries. ${ }^{[14]}$

Concerning the research question and according to the following result section, nurses can determine some of the factors that promote or hinder compliance of pregnant women to health education. As regards the factors that are perceived by pregnant women related to themselves, the majority of them reported that physical and psychological conditions, self-cooperation, and relationship with health staff, were the apparent promoting factors for health education compliance. These factors were clearly linked with women health aspects and their self-efficacy and self-dependency during prenatal care. These findings were in accordance with Gharaibeh et al., in 2005 who explained that physical and psychological health variations among pregnant women encourages them to seek and follow counseling support. Besides, Root and Browner in 2001, clarified that client cooperation with health professionals had an excellent effect in use of health education given. Harmoniously, Fathi and Abdel Azize in 2015 illustrated that noncooperation from clients and their families regarding health communication might result in health problems and poor teaching obedience. Dissimilar with the previous result of Fathi et al., in 2015, which mentioned that physical and psychological conditions were obvious obstacles in seeking health services and applying health teaching. Also, there was notable noncooperation between the clients and health staff that led to avoidance of utilization of health messages. ${ }^{[3,15,17,18]}$ Of course, health education should be followed and adhered by energetic contributions from the pregnant women, but the perceived promoting factors may be perceived as hindering ones for some of women. So, the recognition of the factors can vary greatly in comprehension. Women's cooperation in health education obedience should be linked to the relation with health professionals and their level of self-care dependency.

On the other hand, great proportions of the subjects offered their views that concentration and understanding, acceptance, trust, and health beliefs were the most factors in hindering health education compliance. Learning readiness in pregnant women and trust in health education were the basis of the health education process and the lack of both may negatively affect health learning compliance. Congruent with this result, Awasthi and Bhandariin, 2006, stressed that any health care client has a unique learning capability, with different understanding and retention or cognitive readiness. Clients have multiple influences on their health education goals. Also, Volandes et al., in 2008, discussed that trustful health communication shapes client-nurse relationships. It is the duty of the health professional to confirm the credibility of the delivered health teaching which should be congruent to clients' values and beliefs. ${ }^{[19,20]}$ According to pregnant women values and health beliefs, the nurse as a health educator should tailor the health information to be attractive, trustworthy, clear and matched to the audience's comprehension. The nurse should be a credible source of information.

Pertaining to the factors that were perceived by the study 
participants related to social and economic aspects, high proportions of them mentioned that friends and relatives, family relationships, and marital age were the obvious promoting factors for health education compliance. In the Egyptian community, the family and social relations have an impact on health beliefs and health care attainment. In the same line with this result, Russell et al., in 2003, emphasized that there are minimal studies that discuss the relationship between social and economic context and therapeutic noncompliance. Social support has an observed influence on consuming health care services. Likewise, health care choices were strongly linked within a social and economic framework, which was also tied to the length of marriage. Parallel to this view, Jin et al., in 2008, concluded that social provision and economic maintenance aided clients in increasing desirable attitudes toward obeying treatment, care management and therapeutic health education. Social aspects and years of marriage can activate motivation and remembrance in applying treatment and health advice as well. Contradictory, in Egypt, Abd El Mohsen in 2009, found that social relations and family authority were great barriers for health education compliance. ${ }^{[2,8,21]}$ In general, regarding Egyptian society, the family and particularly the mother of the husband, is considered to have the power of decision making and health care advice. Thus, social and economic influences as perceived by pregnant women can be promoting or hindering factors on health education compliance.

However, the majority of the pregnant women found that monthly income, family size and transportation were the most noticeable factors that inhibit education compliance. Transportation and income aspects were considered as economic factors as mentioned above. Harmonious with this finding, Bier et al., in 2008, reported that there was a gap among compliance and feasibility of doing, which was encountered by the healthcare client. A collection of cultural, societal, and family size influences have a clear impact on individual behaviors regarding adherence to health counseling. Also, supporting this point, Poter in 1996, explored the social tie of family members and provided challenging insights for pregnant women, and offered different authoritative knowledge that negatively affects women's health choices and compliance to antenatal education. ${ }^{[3,22,23]}$

According to the factors that were perceived by study participants related to the health staff and setting, a high percentage of them mentioned that the most factors that affected positive health education compliance were staff cooperation and teaching materials and content. Thus, space and the environment of teaching, showed a great impact on learning compliance in health education. In conformity to this finding, Bergströmin 2014, explained that some researches described

Published by Sciedu Press that the health setting and learning environment, with appropriate organization of instructional location and content, were considered to be important indicators for learners in construction of own learning and implementation. Additionally, in Egypt, Rashdan in 2007 found that there are a lot of reforms that can activate the development of professional nursing in health education. ${ }^{[24,25]}$ Appropriate educational settings for pregnant women, health education materials and staff initiations in the improvement of working conditions in hospitals, will improve women's compliance to health instructions.

Regarding inhibiting factors for health education compliance, for the health setting and staff, the majority of pregnant women viewed that staff knowledge and training, health communication skills, and health education time were the obvious factors. Without doubt, the nurse as a health educator should have enough knowledge, skills and abilities to carry out the responsibility of health education. If the nurse were incompetent, it would hamper client comprehension resulting in noncompliance. Congruent to this result, Fathi and Abdel Azize in 2015, described that nurses in Egypt have very limited knowledge and skills in the assessment, planning, implementation and evaluation of the health education process. They are overwhelmed by tasks and have no time for preparation of that valuable process. However, Abd El Mohsen in 2009 stressed that the nurse, as a health educator, must be equipped with recent and accurate knowledge and skills in teaching and also ought to be familiarized with the education, communication, and social skills needed to create appropriate health education interventions. As well, nurses must find suitable time for health education. ${ }^{[8,17]}$ Hence, from both positive and negative perspectives in health education, the negative effects on health education compliance need to be reduced. At the same time, effective strategies to enhance positive factors must be used as much as possible.

Finally, the study subjects ranked the satisfactory topics that they received and adhered to be implemented. These topics were about pregnancy follow up, which took the first rank and dangerous signs which came next. This ranking reflected that both topics seemed to be the most important issues to the pregnant women. As a result, they understood and applied instructions with satisfaction and in a compliant manner. In agreement with this finding, Root and Browner in 2001, reported that the most important subjective issues for the pregnant women were the appointments, awareness of nutrition, and pregnancy danger signs. But incongruent to these, Mersal et al., in 2013, documented that the most important parameters and knowledge needed by pregnant women were antenatal measurements and hygiene. ${ }^{[2,4]}$ Most of all, health education topics for pregnant women, should 
be prepared and implemented in an organized, scientific and credible process. It should be offered by trained and knowledgeable nurses as health educators. This would contribute great benefits to health education compliance and the health education paradigm in pregnancy.

\section{Conclusions}

Compliance to health education among pregnant women is a major health concern affecting almost all women, particularly in pregnancy period. There are a lot of factors that may promote or inhibit health education compliance among pregnant women, such as factors in women themselves, social and economic factors, and health staff and setting factors. Moreover, follow up and dangerous signs are the satisfactory topics in health education compliance as mentioned by study subjects.

\section{Recommendations and further studies}

Nurses, as health educators, must facilitate the educational process for pregnant women, family and society. Efforts and collaboration between all nursing disciplines in the field of health education are needed. The present study suggests the following further studies:

- Repetition of the current study with a qualitative methodology.

- Development and implementation of health education programs for nurses and pregnant women to help them in managing obstacles that may face them during pregnancy.

- Application of health education models as a guide for training nurses in the health education process.

- Determination of the resources and facilities for health education in obstetric and reproductive hospitals in Egypt.

- Collaboration, guidance and support for pregnant women in managing common health education barriers.

\section{CONFLicts OF InTEREST Disclosure}

The authors declare they have no conflict of interest.

\section{REFERENCES}

[1] World Health Organization. Integrated Management of Pregnancy And Childbirth. Managing Complications in Pregnancy and Childbirth: A guide for midwives and doctors. Department of Reproductive Health and Research. 2007; 2-55.

[2] Jin J, Sklar G, Oh S, et al. Factors affecting therapeutic compliance: A review from the patient's perspective. National Center for Biotechnology Information, U.S. National Library of Medicine TherClin Risk Manag. 2008; 4(1): 269-286.

[3] Root R, Browner CH. Practices of the pregnant self: compliance with and Resistance to prenatal norms. Culture, Medicine and Psychiatry Kluwer Academic Publishers. 2001; 25: 195-223. https: //doi.org/10.1023/A:1010665726205

[4] Mersal FA, Esmat OM, Khalil GM. Effect of prenatal counseling on compliance and outcomes of teenage pregnancy. Eastern Mediterranean Health Journal 2013; 19(1): 10-17. PMid: 23520900.

[5] Mukhopadhyay P, Chaudhuri RN, Paul B. Hospital-based perinatal outcomes and complications in teenage pregnancy in India Journal of Health, Population \& Nutrition. 2010; 28(5): 494-500. https://doi.org/10.3329/jhpn.v28i5.6158

[6] Inkster ME, Donnan PT, MacDonald TM, et al. Adherence to antihypertensive medication and association with patient and practice factors. J Hum Hypertens. 2006; 20: 295-7. PMid: 16424861. https://doi.org/10.1038/sj.jhh.1001981

[7] Elixhauser A. Complicating Conditions of Pregnancy and Childbirth. Healthcare Cost and Utilization Project (HCUP). U.S. Agency for Healthcare Research and Quality. 2011; 1-12.

[8] Abd El Mohsen A. Barriers Encountered by Undergraduate Nursing Students While Providing Health Education for Patients. Unpublished Master Thesis. Faculty of Nursing, University of Alexandria. 2009; 34-12.
[9] Nichols M, Roux G, Harris N. Primigravid and multigravida women: prenatal perspectives. Journal of Perinatal Education. 2007; 16(2): 21-32. PMid: 18311335. https://doi.org/10.1624/10581240 7 X192019

[10] Enriquez M, Farnan R, Simpson K, et al. Pregnancy, poverty, and HIV. Journal of Nurse Practitioners. 2007; 3(10): 687-93. https: //doi.org/10.1016/j.nurpra.2007.08.015

[11] Mukhopadhyay P, Chaudhuri RN, Paul B. Hospital-based perinatal outcomes and complications in teenage pregnancy in India. Journal of Health, Population \& Nutrition. 2010; 28(5): 494-500. https://doi.org/10.3329/jhpn.v28i5.6158

[12] Fathi A, Anwar A, Abu Darie M. "Men in Nursing" As Viewed by Male Students in Secondary Schools. Clinical Nursing Studies. 2016; 4(2): 41-47.

[13] Gaber M, Mostafa M. Comparison of Nursing Students' perceptions about Male Nursing among Zagazig University in Egypt and Shaqra University in Saudi Arabia. Life Science Journal. 2013; 10(4).

[14] Ibrahim SE, Ibrahim BL. Egypt's population policy: the long march of state and civil society. In: Jain A, ed. Do population policies matter? Fertility and politics in Egypt, India, Kenya and Mexico. New York: Population Council; 1998.

[15] Gharaibeh M, AL-Ma'aitah R, AL Jada N. Lifestyle practices of Jordanian pregnant women. International Nursing Review. 2005; 52 : 92-100. PMid: 15842321. https://doi.org/10.1111/j.1466 $-7657.2005 .00257 . \mathrm{x}$

[16] Indonesia Demographic and Health Survey 2070. Calverton, Maryland, Badan Pusat Statistik, National Family Planning Coordinating Board, Ministry of Health and ORC Macro. 2008.

[17] Ibrahim AF, Abdelaziz TM. Health education barriers, encountered by nurses at oral healthcare units. International Journal Of Bioassays. 2015; 4(5): 3866-3875. 
[18] Ibrahim AF, Tawfik FM, Akel DT. Nurse communication in health education: Patients' perspective. Clinical Nursing Studies. 2015; 3(4): 94-102.

[19] Awasthi SH, Bhandari M. Identification and Prioritization of Barriers to Quality Performance in Medical Education and Patient Care, Medical University in India, Kamla-Raj. 2006; 13(2): 157-162.

[20] Volandes A, Ariza M, abbo E, et al. Overcoming Educational Barriers for Advance Care Planning in Latinos with Video Images. Journal of palliative medicine. 2008; 11(5): 700-6. PMid: 18588401. https://doi.org/10.1089/jpm.2007.0172

[21] Russell S, Daly J, Hughes E, et al. Nurses and 'difficult' patients: negotiating non-compliance. Journal of Advanced Nursing. 2003; 43(3): 281-287. PMid: 12859787. https ://doi.org/10.1046/j . 1365-2648.2003.02711.x
[22] Bier D, Derelian D, German B, et al. Improving Compliance With Dietary Recommendations: Time for New, Inventive Approaches? Nutrition Today. 2008; 43(5): 180-187. https://doi.org/10.1 097/01.NT.0000338564.14317.69

[23] Porter S. Contra-Foucault: Soldiers, Nurses and Power (Michel Foucault). Sociology. 1996; 30: 59-79. https://doi.org/10.1177/ 0038038596030001005

[24] Bergström H, Elinder LS, Wihlman U. Barriers and facilitators in health education for adults with intellectual disabilities - a qualitative study. Oxford Journals. 2014.

[25] Rashdan T. Implications for Advancement of Egyptian Nursing: Input equals Output. Doha, White Paper for Fulbright Academy Workshop. 2007. Available from: http: //www.fulbrightacademy.org/file_depot/0-10000 000/20000-30000/21647/folder/70366/Implications+f or+Advancement+of+Egyptian+Nursing+-+Rashdan.pdf 